\title{
Degradación de celulosa y xilano por microorganismos aislados de dos tipos de compost de residuos agrícolas en la Sabana de Bogotá
}

\section{Degradation of cellulose and xylan by microorganisms isolated in two different compost from agricultural wastes in the Bogota Plateau}
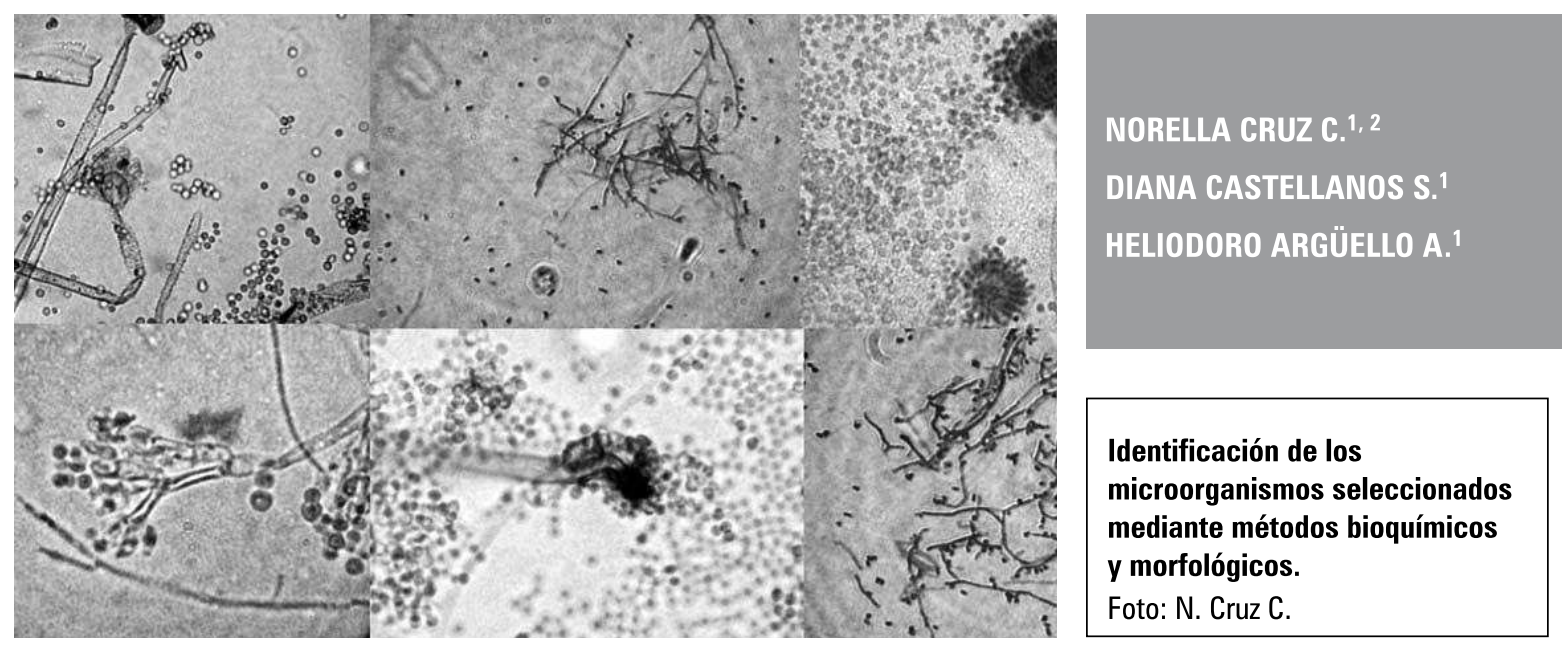

\section{RESUMEN}

En el mundo los residuos vegetales son el recurso renovable más grande que existe y están compuestos en su mayor parte por celulosa y hemicelulosa, sustancias que son degradadas por microorganismos. En Colombia se conoce poco acerca de la biodiversidad microbiana y su función en la naturaleza. A manera de línea base en esta investigación se aislaron microorganismos degradadores de celulosa y xilano en dos compost provenientes de residuos agrícolas, el primero de una finca de flores (1) y el segundo de hortalizas (2), ubicadas en la Sabana de Bogotá. El aislamiento se realizó en medios de cultivo con extracto de compost, los morfotipos se purificaron y se les evaluó la actividad enzimática a nivel cualitativo en medios sólidos con xilano y celulosa. Se seleccionaron los mejores microorganismos para cada actividad en cada compost y se les cuantificó proteínas extracelulares, biomasa y actividad degradadora en los respectivos sustratos. El compost 2 fue mejor para el aislamiento de microorganismos degradadores de xilano y celulosa que el compost 1 . Se encontraron 46 microorganismos con potencial para degradar xilano y cinco para celulosa de estos se evaluaron seis para xilano y cinco para celulosa, de los cuales, el hongo Aspergillus sp. 1 del compost 1 y el hongo Penicillium sp. y el actinomiceto Streptomyces sp. 2 del compost 2 son promisorios para la degradación de xilano, el hongo Aspergillus sp. 2 y el actinomiceto Streptomyces sp. 3 del compost dos para degradar celulosa.

1 Grupo de Investigación AGRAS, Departamento de Agronomía, Facultad de Agronomía, Universidad Nacional de Colombia, Bogotá (Colombia).

2 Autora para correspondencia: norellita@gmail.com 


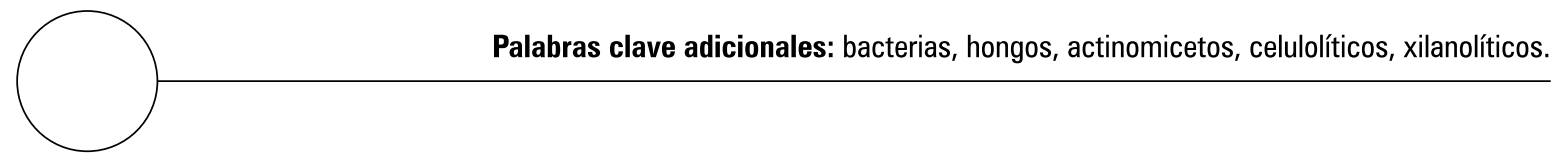

ABSTRACT

In the world, the vegetable wastes are the largest renewable resource that exists and are composed mostly of cellulose and hemicellulose, the substances that can be degraded by microorganisms. In Colombia, there is few knowledge about microbial biodiversity and its use. As a base line in this study, there were isolated degraders microorganisms of cellulose and xylan from two compost from agricultural waste, the first one from a floriculture farm (1) and the second one from a vegetable farm (2), located in the Bogotá Plateau. The isolation was carried out using selective mediums with compost extracts. Then, it was performed morphotype identification and qualitative evaluation of enzymatic activities in specific solid mediums with xylan and cellulose. The best microorganisms were selected for each activity in each compost and extracellular proteins, biomass and activity in the respective substrates were quantified. The compost 2 was better for isolation of xylan and cellulosa degraders than compost 1 . We found 46 microorganisms with a potential to degrade xylan and five microorganisms with a potential to degrade cellulose, from these were evaluated six for xylan and five for cellulose, of which the fungi Aspergillus sp. 1 from compost 1, the fungi Penicillium sp. and the actinomycete Streptomyces sp. 2 from compost 2 were promising for the degradation of xylan, the fungus Aspergillus sp. 2 and the actinomycete Streptomyces sp. 3 from compost 2 were promising to degrade cellulose.

Additional key words: bacteria, fungi, actinomycetes, cellulolytics, xylanolytics.

Fecha de recepción: 20-07-2009

Aprobado para publicación: 30-11-2009

INTRODUCCIÓN

En el mundo, los residuos vegetales son el recurso renovable más grande que existe y se considera que más del $85 \%$ de los residuos considerados agrícolas y un gran porcentaje de residuos agroindustriales son de este tipo (Sztern y Pravia, 1999). Estos residuos están compuestos en su mayor parte por celulosa, hemicelulosa y lignina (Paul y Clark, 1996). Los compuestos lignocelulolíticos se estiman en varios miles de millones de toneladas anuales (Okeke y Obi, 1994) y los microorganismos cumplen un papel fundamental en su descomposición y transformación (Saber, 2001).

Por esta razón se han desarrollado procesos usando estos residuos como materia prima para la obtención de compost (Suquilanda, 1996), pero también de productos con valor agregado como etanol, enzimas microbianas, y proteínas unicelulares (Oliveira et al., 2006). En el proceso de compostaje los microorganismos participan por medio de la secreción de enzimas hidrolíticas que tienen un papel fundamental en la depolimerización de los componentes orgánicos de los diferentes residuos (Marx et al., 2001). Entre estas enzimas las más importantes son las celulasas, hemicelulasas, proteasas, lipasas, fosfatasas y arilsulfatasas (Mondini et al., 2004).

Cuando las enzimas que producen los microorganismos son extracelulares pueden ser potencialmente útiles, en la degradación de diferentes sustratos. Estas enzimas extracelulares tienen ventajas con respecto a las intracelulares porque 
no necesitan técnicas de ruptura, para ser extraídas, presentan una estructura más compacta y son menos susceptibles a la degradación. Las enzimas extracelulares hidrolizan moléculas grandes como almidón, celulosa, hemicelulosa, pectina, proteínas, lípidos y ácidos nucleicos, que son asimiladas por los microorganismos como fuente de carbono y energía. Moléculas como hemicelulosa y celulosa están presentes en gran cantidad en el compost proveniente de residuos agrícolas (Sztern y Pravia, 1999) y esto lo convierte en un sustrato ideal para el aislamiento de microorganismos degradadores de estas sustancias.

Los microorganismos aislados de compost se pueden usar para la producción de inoculantes que apoyen la producción agrícola en el control de plagas, como fertilizantes (ICA, 2007), o para mejorar tiempos en procesos de compostaje elaborados con residuos agrícolas (Vargas-García et al., 2005). Adicionalmente, el uso de enzimas microbianas, especialmente celulasas y xilanasas extracelulares, ha ganado importancia debido a que los productos obtenidos de la hidrólisis (azúcares solubles) son indispensables en procesos de fermentación, producción de combustibles, químicos y alimentos (Kuhada et al., 1998).

La literatura reporta muchos microorganismos con capacidad para degradar xilano principalmente hongos (Pham et al., 1998). Los hongos filamentosos producen gran cantidad de xilanasas extracelulares en comparación con las levaduras y bacterias (Kulkarni et al., 1999). Para la degradación de celulosa han sido estudiados muchos géneros de hongos por sus enzimas celulolíticas (Lynd et al., 2002) y entre las bacterias, los actinomicetos se destacan por su capacidad degradadora de este sustrato (Lynd et al., 2002).

En Colombia la biodiversidad microbiológica es prácticamente desconocida y por consiguiente su función en la naturaleza, posiblemente porque en el pasado no se contaba con metodologías apropiadas para el aislamiento, purificación, clasificación, caracterización y preservación de los microorganismos (Melgarejo et al., 2002). Actualmente en el Instituto Colombiano Agropecuario (ICA) se encuentran registrados algunos productos acondicionadores de suelo y abonos orgánicos, elaborados a partir de microorganismos, vermicompost, estiércoles y compost (ICA, 2008). En este contexto, dichos trabajos generan un entorno favorable para el desarrollo de esta investigación a manera de línea base, en la que se pretende aislar bacterias y hongos con capacidad de degradar sustancias presentes en procesos de descomposición de residuos agrícolas como celulosa y hemicelulosa.

\section{MATERIALES Y MÉTODOS}

\section{Recolección de muestras}

El primer compost provino de la finca Jardines de Chía Ltda., la cual se encuentra ubicada en la vereda la Fagua, Chía, Cundinamarca. Esta finca se dedica al cultivo de flores como pompón de exportación. En esta finca el compost es elaborado únicamente con tallos y flores de pompón triturados $\mathrm{y}$ dispuestos en pilas de aproximadamente $3 \mathrm{~m}$ de alto, $4 \mathrm{~m}$ de ancho y $4 \mathrm{~m}$ de largo (basal) y son volteadas cada 15 días y una relación $\mathrm{C} / \mathrm{N}=14$.

El segundo compost provino de la finca Gabeno, ubicada en el km 10 vía Tenjo, Cundinamarca. Esta finca se dedica al cultivo de hortalizas orgánicas principalmente lechuga. El compost se elabora con residuos de hortalizas y plantas arvenses sin limpiar como resultado de las desyerbas manuales de los cultivos y se le adiciona melaza y estiércol bovino. En esta finca el compost se realiza en pilas de 2,5 $\mathrm{m}$ de ancho, $10 \mathrm{~m}$ de largo y $1,5 \mathrm{~m}$ de alto, la pila se cubre con pasto cortado, para protegerla de la pérdida de humedad por evaporación, no se voltea a menos de que un exceso de humedad así lo exija. Para el caso del compost trabajado se realizaron tres volteos debido a las lluvias y una relación $\mathrm{C} / \mathrm{N}=13$. 
Se tomaron tres muestras de cada compost en diferentes tiempos de acuerdo con la duración de cada uno de los procesos de compostaje. El compost 1 ( 5 meses de compostaje) se muestreó a las 2 semanas, a los 3 meses y a los 5 meses. El compost 2 ( 8 meses de compostaje) a las 2 semanas, a los 4 meses y a los 8 meses. Para cada muestra se tomaron 10 puntos diferentes de la pila cubriendo el interior (5 puntos) y el exterior de la pila (5 puntos), los cuales se mezclaron en un recipiente limpio y se sacaron tres submuestras.

\section{Aislamiento de microorganismos}

Cada submuestra se procesó de manera independiente por triplicado. Para cada una se utilizó un medio de cultivo con extracto de compost de cada muestra (Hunter-Cevera et al., 1986) y bactoagar (Difco). El aislamiento se realizó en medios no selectivos con el fin de obtener microorganismos que degradaran sustratos complejos como el compost, de esta manera poder probar su acción sobre diferentes sustratos presentes en compost realizado con residuos agrícolas en este caso celulosa y xilano. A los medios para actinomicetos se les adicionó el antibiótico nistatina y en los medios para hongos se utilizó el antibiótico cloranfenicol (Hunter-Cevera et al., 1986). Para el procesamiento de las muestras se empleó la técnica de diluciones seriadas (Madigan et al., 2001).

\section{Determinación cualitativa de las diferentes actividades}

A todos los microorganismos aislados se les evaluó su actividad en los dos sustratos xilano y celulosa por duplicado, para tal fin se realizaron inóculos líquidos cuyas concentraciones se ajustaron para bacterias a $10^{7} \mathrm{ufc} / \mathrm{mL}$ de acuerdo con el patrón de Mc Farland, para actinomicetos a $10^{6}$ células $/ \mathrm{mL}$ y para hongos a $10^{5}$ células $/ \mathrm{mL}$ por medio de conteos en cámara de Neubauer. Cada suspensión microbiana a evaluar se inoculó sobre círculos de papel filtro, ubicados en la parte central de las cajas de petri que contenían los medios sólidos. Estos medios fueron elabora- dos como sigue: $10 \mathrm{~g}$ de sustrato, $1 \mathrm{~g} \mathrm{KH}_{2} \mathrm{PO}_{4}, 2$ $\mathrm{g} \mathrm{NaNO}_{3}, 0,5 \mathrm{~g} \mathrm{MgSO}_{4} 7 \mathrm{H}_{2} \mathrm{O}, 10 \mathrm{~mL}$ solución de elementos traza, $990 \mathrm{~mL}$ agua destilada y bactoagar $15 \mathrm{~g}$. Se ajustaron a $\mathrm{pH} 6$ y se esterilizaron por $10 \mathrm{~min}$ a $15 \mathrm{Lb}$ (Cooper y Wood, 1980). Los sustratos fueron CMC (carboximetil celulosa Sigma) y xilano de hojuelas de avena (Sigma).

En cada una de las cajas se midió el crecimiento de la colonia y el halo de degradación alrededor de la misma a las $116 \mathrm{~h}$ para actinomicetos y a las $48 \mathrm{~h}$ para bacterias, sacando un porcentaje de degradación (Pedroza et al., 2007). Adicionalmente se categorizó la intensidad del halo de 1-3 siendo 1 un halo débilmente visible y 3 un halo muy visible con el fin de dar una idea de la intensidad de la actividad enzimática sobre el sustrato específico.

\section{Actividad enzimática de los mejores aislamientos}

De los microorganismos evaluados en la etapa anterior se escogió el mejor de cada compost, de cada grupo microbiano y de cada actividad. El microorganismo con el mayor porcentaje y el mayor grado fue seleccionado para esta etapa. Se escogieron seis microorganismos por cada una de las actividades xilano y celulosa, de los cuales dos corresponderían a bacterias, dos a hongos y dos a actinomicetos, uno de cada compost.

Se prepararon inóculos de concentración conocida. De cada una de estas suspensiones microbianas se extrajo $1 \mathrm{~mL}$ y se inoculó sobre $3 \mathrm{~mL}$ del medio líquido. Estos medios líquidos fueron preparados de la misma forma que los medios sólidos del ensayo anterior. Los medios líquidos inoculados se incubaron a $28^{\circ} \mathrm{C}$ en agitación constante a $130 \mathrm{rpm}$. Para bacterias se tomaron muestras cada $6 \mathrm{~h}$ durante $48 \mathrm{~h}$, para hongos y actinomicetos cada 24 h por $4 \mathrm{~d}$ (Mikan y Castellanos, 2004).

La muestra se centrifugó a $6.000 \mathrm{rpm}$ y el pelet fue puesto a secar en un horno a $105^{\circ} \mathrm{C}$ por $24 \mathrm{~h}$ con el fin de determinar la biomasa seca 
microbiana. Los sobrenadantes se congelaron en nitrógeno líquido para la evaluación posterior de las actividades enzimáticas. A partir de los sobrenadantes, se realizó la determinación de las proteínas extracelulares utilizando el método de Zor y Selinger (1996), y la determinación de actividades enzimáticas.

Actividad-ß-1,4-endoglucanasa: a $200 \mu \mathrm{L}$ de sobrenadante, se adicionó $875 \mu \mathrm{L}$ de CMC al 1\% (Sigma) y $25 \mu \mathrm{L}$ de buffer acetato de sodio $1,0 \mathrm{M}$ (Ramírez y Coha, 2003) con pH 6,0 para bacterias y actinomicetos y $\mathrm{pH} 5,3$ para hongos.

Actividad-ß-1,4-exoglucanasa: se colocaron 12,5 mg de papel filtro Whatman No. 1 en un tubo Eppendorf al cual se le agregaron $200 \mu \mathrm{L}$ de buffer acetato de sodio $0,6 \mathrm{M}$ con $\mathrm{pH}$ 6,0 para bacterias y actinomicetos (Ramírez y Coha, 2003) y pH 5,3 para hongos y $800 \mu \mathrm{L}$ de sobrenadante.

Actividad-ß-1,4-glucosidasa: se determinó utilizando $250 \mu \mathrm{L}$ del sobrenadante y $250 \mu \mathrm{L}$ de salicina $10 \mathrm{mM}$ en buffer acetato de sodio $1 \mathrm{M}$ (pH 6,0) para bacterias y actinomicetos (Ramírez y Coha, 2003) y pH 5,3 para hongos.

Todos los sistemas se incubaron a $50^{\circ} \mathrm{C}$ (temperatura ideal para la acción de enzimas celulolíticas) por 50 min. Posteriormente se midió la liberación de azúcares reductores por el método del arsenomolibdato de Nelson (1944) y Somogyi (1952). La absorbancia se leyó en un lector de microplacas BIORAD 680XR a $655 \mathrm{~nm}$. Las actividades se expresaron en UI por $\mathrm{mL}$. Considerando una unidad la cantidad de enzima que libera $1 \mu \mathrm{M}$ glucosa/min (Ramírez y Coha, 2003).

Actividad-ß-1,4endo-xilanasa: se inocularon $50 \mu \mathrm{L}$ del sobrenadante en $450 \mu \mathrm{L}$ de suspensión de xilano de hojuelas de avena (Sigma) al 0,5\% en buffer citrato pH 5,5 (Bailey et al., 1992). Se incubó por $5 \mathrm{~min}$ a $50^{\circ} \mathrm{C}$ y se midió la liberación de azúcares reductores por el método DNS (Miller, 1959), usando xilosa como solución estándar. Las unidades de actividad fueron expresadas en nKat/s (cantidad de enzima necesaria para transformar un nmol de sustancia por segundo). La absorbancia se leyó en un espectrofotómetro (Biomate 3) a $540 \mathrm{~nm}$.

\section{Manejo de datos}

Para la evaluación cuantitativa de actividades enzimáticas todos los datos se tomaron por triplicado, se calculó la desviación estándar y se utilizó estadística descriptiva para realizar las curvas de calibración de cada actividad en el programa Excel. Se determinaron las respectivas correlaciones entre las curvas de biomasa y proteínas solubles con las actividades en cada sustrato utilizando el programa Excel. Las gráficas se realizaron en el programa Sigma Plot versión 10.

\section{Preservación final de cepas}

Los microorganismos aislados se conservaron en tubos eppendorf, con el sustrato especifico $1 \%$ (xilano, celulosa) en medio líquido, en caso de no presentar actividad en ninguno de estos sustratos se preservaron en extracto de compost y se les adicionó glicerol al 10\% (p/v). La concentración de células para bacterias fue de $10^{7} \mathrm{ufc} / \mathrm{mL}$ y hongos filamentosos $10^{6}$ esporas $/ \mathrm{mL}$. Cada microorganismo se conservó por triplicado a $-70^{\circ} \mathrm{C}$.

\section{Identificación de cepas seleccionadas}

Los hongos y los actinomicetos seleccionados para la parte final fueron identificados de acuerdo con métodos morfológicos y las bacterias de acuerdo a métodos bioquímicos utilizando los Kit clínicos de identificación BBL Crystal y API de Biomeriux.

\section{RESULTADOS Y DISCUSIÓN}

\section{Aislamiento de microorganismos}

Se aislaron y se preservaron en agar compost, 125 morfotipos en el compost 1 (19 de actino- 
micetos, 67 de bacterias y 39 de hongos), y 164 morfotipos del compost 2 (65 de actinomicetos, 79 de bacterias y 20 de hongos).

\section{Actividad cualitativa}

De acuerdo con la evaluación de las actividades hidrolíticas cualitativas "presencia de halo de degradación", se encontró que el compost 1 presentó mayor número de morfotipos con algún grado de degradación sobre los sustratos estudiados especialmente xilano (102), sin embargo en los dos compost fue mayor el número de morfotipos degradadores de xilano que de celulosa (figura 1).

De acuerdo con los porcentajes e intensidad del halo de degradación (G) se encontraron 46 microorganismos con potencial para la degradación de xilano $(\%>40, G=3) 19$ del compost 1 y 23 del compost 2 , en su mayoría actinomicetos, mientras que para celulosa solo dos presentaron porcentajes superiores al 20 y grado 3 de degradación y fueron aislados del compost 2 (tabla 1). Por esta razón en celulosa se utilizaron para la evaluación cuantitativa solo cinco microorganismos, dos con grado 3 y tres con grado 2 de degradación

\section{Microorganismos seleccionados}

En la tabla 2 se muestran los morfotipos seleccionados por tener el mayor porcentaje de degradación y mayor grado dentro de cada sustrato, compost y grupo microbiano. Se encontraron los siguientes generos: Bacillus, Aspergillus, Penicillium y Streptomyces (se numeraron sp. 1, sp. 2, sp. 3, sp. 4) de acuerdo a la cantidad de microorganismos diferentes dentro del género a evaluar, con el fin de diferenciarlos.

Dentro de los morfotipos, la bacteria Bacillus sp.2 del compost 2 presentó la mejor degradación en xilano y en celulosa, y se seleccionó para calcular la actividad cuantitativa en los dos sustratos, a pesar de que su grado de degradación en celulosa es 2 . En el caso de los hongos, Aspergillus sp. 1 del compost 1 fue el que tuvo la mayor actividad en xilano y en celulosa dentro de los hongos en este

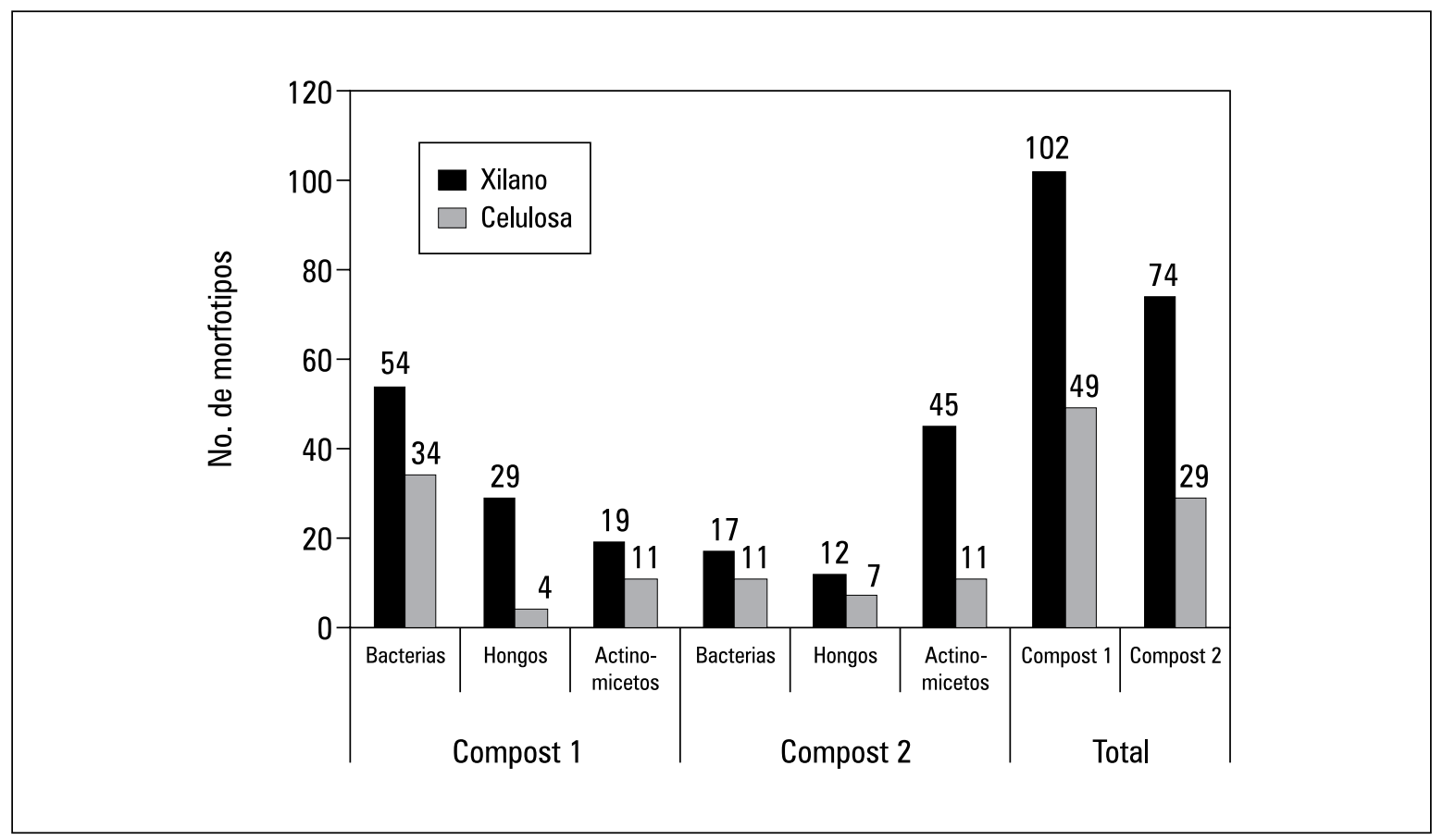

Figura 1. Número de morfotipos de microorganismos que presentaron actividad cualitativa en xilano y celulosa (Cooper y Wood, 1980) en los compost provenientes de residuos agrícolas en la Sabana de Bogotá. 


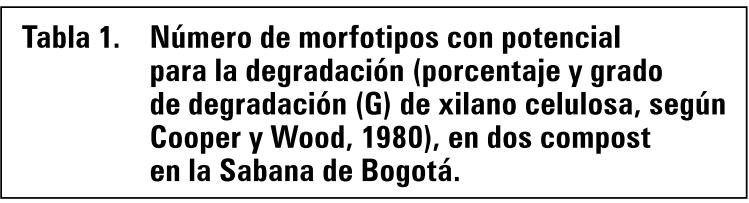

\begin{tabular}{|l|l|r|c|}
\hline \multirow{4}{*}{ Compost } & Microorganismo & $\begin{array}{c}\text { Xilano } \\
\%>40 \% \\
\mathrm{G}=3\end{array}$ & $\begin{array}{c}\text { Celulosa } \\
\text { Com }>20 \% \\
\mathrm{G}=3\end{array}$ \\
\hline \multirow{3}{*}{ Compost 1 } & Bacterias & 7 & 0 \\
\cline { 2 - 4 } & Hongos & 2 & 0 \\
\cline { 2 - 4 } & Actinomicetos & 10 & 0 \\
\hline \multirow{3}{*}{ Total } & Bacterias & 0 & 0 \\
\cline { 2 - 4 } & Hongos & 4 & 1 \\
\cline { 2 - 4 } & Actinomicetos & 23 & 1 \\
\hline
\end{tabular}

compost, así que también se trabaja de aquí en adelante con el mismo hongo en los dos sustratos aunque su grado de degradación en celulosa es 2. No se encontraron bacterias con potencial para degradar celulosa en el compost 1 (tabla 2).

\section{Actividad cuantitativa}

\section{Actividad en xilano}

La figura 2 muestra las correlaciones entre las variables proteínas solubles, biomasa y actividad endoxilanasa en todos los microorganismos evaluados. A medida que aumentan las proteínas solubles aumenta la degradación sobre el sustrato y por consiguiente el microorganismo puede au- mentar su biomasa al utilizar los azúcares solubles provenientes de la degradación del sustrato para su crecimiento.

En las figuras $2 \mathrm{~A}$ y $2 \mathrm{~B}$ se muestra una mayor correlación entre las variables para Penicillum sp. $(>0,9)$ que para Aspergillus sp. $1(>0,7)$ y la biomasa tiene menor correlación con la actividad endoxilanasa $(0,71)$ y las proteínas solubles $(0,78)$, su valor máximo de biomasa es mayor a la del hongo del otro compost aunque su actividad sobre el sustrato es menor.

En diferentes estudios realizados con hongos se ha encontrado que la actividad enzimática de la endoxilanasa depende mucho de la especie evaluada, la actividad de la enzima puede tener máximo de actividad en diferentes $\mathrm{pH}$ y temperaturas (Curotto et al., 1994; Ferreira et al., 1999; Abdel-Sater y El-Said, 2001; Oliveira et al., 2006). Para el trabajo realizado, el hongo Aspergillus sp. 1 aislado del compost 1 tiene mayor actividad que el hongo Penicillum sp. aislado del compost 2.

Especies de los géneros Aspergillus pueden producir xilanasas libres de celulasas usando xilano como única fuente de carbono (Kulkarni et al., 1999). El género Penicillum está registrado como otro de los géneros además de Aspergillus y Trichoderma con gran cantidad de especies que degrada xilano y produce todas las enzimas extracelulares implicadas en la degradación del mismo (Chávez et al., 2006).

Tabla 2. Morfotipos seleccionados de acuerdo con su porcentaje y grado de degradación (G) en xilano y celulosa aislados en dos compost de la Sabana de Bogotá.

\begin{tabular}{|c|c|c|c|c|}
\hline & & Bacterias & Hongos & Actinomicetos \\
\hline \multirow{4}{*}{ Compost 1} & Xilano & Bacillus sp. 1 & Aspergillus sp. 1 & Streptomyces sp. 1 \\
\hline & $\%$ y grado & $77,5 \% \mathrm{G}=3$ & $66,9 \% \mathrm{G}=3$ & $57,7 \% \mathrm{G}=3$ \\
\hline & Celulosa & - & Aspergillus sp. 1 & Streptomyces sp. 4 \\
\hline & $\%$ y grado & - & $15,4 \% \mathrm{G}=2$ & $43,3 \mathrm{G}=2$ \\
\hline & & Bacterias & Hongos & Actinomicetos \\
\hline \multirow{4}{*}{ Compost 2} & Xilano & Bacillus sp. 2 & Penicillium sp. & Streptomyces sp. 2 \\
\hline & $\%$ y grado & $52,6 \% \mathrm{G}=3$ & $54,8 \% \mathrm{G}=3$ & $62,7 \% \mathrm{G}=3$ \\
\hline & Celulosa & Bacillus sp. 2 & Aspergillus sp. 2 & Streptomyces sp. 3 \\
\hline & $\%$ y grado & $74,0 \% \mathrm{G}=2$ & $34,7 \% \mathrm{G}=3$ & $21,4 \% \mathrm{G}=3$ \\
\hline
\end{tabular}



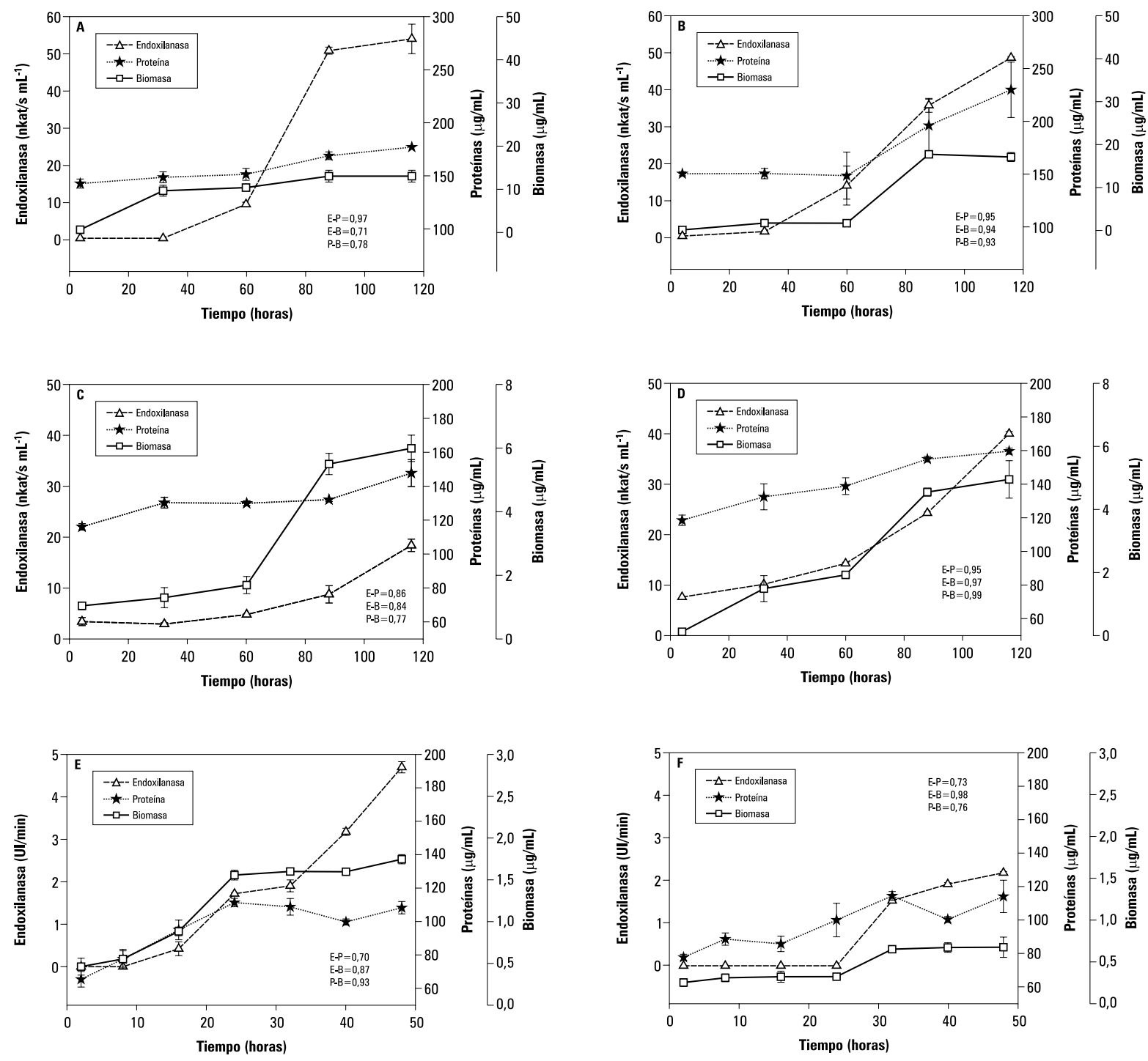

Figura 2. Crecimiento y actividad enzimática xilanolítica de los morfotipos seleccionados. A, Aspergillus sp. 1;

B, Penicillium sp.; C, Streptomyces sp. 1; D, Streptomyces sp. 2; E, Bacillus sp. 1; F, Bacillus sp. 2.

$E$, actividad endoxilanasa; $P$, proteínas solubles; $B$, biomasa. Coeficientes de correlación entre las variables E-P, E-B, P-B.

Para los actinomicetos o bacterias filamentosas se observa que la actividad máxima ocurre a las $116 \mathrm{~h}$ en los dos actinomicetos evaluados sin embargo, se ve claramente que la actividad del actinomiceto Streptomyces sp. 2 aislado del compost $2\left(38,21 \mathrm{nkat} / \mathrm{s} \mathrm{mL}^{-1}\right)$ es mayor que la del actinomiceto Streptomyces sp. 1 aislado del compost $1\left(18,40 \mathrm{nkat} / \mathrm{s} \mathrm{mL}^{-1}\right)$. Aunque este último pre- senta un mayor crecimiento de biomasa (figuras 2C y 2D).

Si expresamos la actividad de los actinomicetos evaluados en términos de unidades internacionales por mililitro, Streptomyces sp. 1 tiene una actividad de 5,52 UI/mL y Streptomyces sp. 2 11,2 $\mathrm{UI} / \mathrm{mL}$. Si comparamos estos valores con algu- 
nos reportados en la literatura, las actividades oscilan entre 12 y $22 \mathrm{UI} / \mathrm{mL}$ con máximos de actividad que ocurren a las $120 \mathrm{~h}$, para actinomicetos mesófilos y termófilos creciendo en sustratos que promueven secreción de xilanasas libres de celulasas, como xilano puro o bagazo de caña (Maheswari y Chandra, 2000; Antanopoulos et al., 2001; Techapun et al., 2002). Entre las bacterias se destacan los géneros Bacillus y Streptomyces por su capacidad de degradar xilano, solo unas pocas especies de Bacillus pueden producir xilanasas libres de celulasas (Kulkarni et al., 1999).

Para las bacterias no filamentosas se puede ver que la bacteria Bacillus sp. 1, aislada del compost 1, presenta una mayor actividad endoxilanasa (15,64 nkat/s mL $\left.\mathrm{mL}^{-1}\right)$ que la bacteria Bacillus sp. 2 del compost $2\left(7,31 \mathrm{nkat} / \mathrm{s} \mathrm{mL}^{-1}\right)$ (figuras $2 \mathrm{E}$ y 2F). Como se mencionó anteriormente la correlación entre las curvas de actividad endoxilanasa y proteínas es buena $(>0,7)$ para los dos Bacillus. Este resultado es similar a lo encontrado por Poorma y Prema (2007) en Bacillus subtilis donde se muestra una tendencia semejante de las curvas de proteínas extracelulares y actividad endoxilanasa hasta las $72 \mathrm{~h}$. Sin embargo ellos encontraron que la actividad máxima ocurrió a las 72 h, en un experimento que duró 120 h, mientras que en nuestro experimento el tiempo máximo muestreado fue 48 h y corresponde con la máxima actividad encontrada.
Si se compara la actividad enzimática cuantificada cualitativa y cuantitativamente de los seis microorganismos evaluados para xilano se puede observar que las bacterias a pesar de que tienen porcentajes de degradación altos a nivel cualitativo, a nivel cuantitativo son los que presentan los valores más bajos de actividad endoxilanasa, $\mathrm{y}$ aunque los hongos y actinomicetos evaluados tienen porcentajes similares, los hongos presentan valores más altos de actividad endoxilanasa (tabla 3). Esto indicaría que el método de selección cualitativo no guarda una relación directa con el método cuantitativo en las cepas seleccionadas, resultados similares fueron encontrados por Morales (2006). Es necesario entonces mejorar el método cualitativo para evaluar degradación de xilano de tal manera que el porcentaje y la intensidad de halo de degradación guarde una relación directa con el método cuantitativo y así poder hacer una mejor selección cuando se tienen gran cantidad de aislamientos. Esto considerando que la selección de microorganismos por el método cualitativo es más rápida y económica que por el método cuantitativo.

\section{Actividad en celulosa}

De los cinco microorganismos celulolíticos seleccionados solo dos presentaron actividad en las pruebas cuantitativas, el hongo Aspergillus sp. 2 y el actinomiceto Streptomyces sp. 3 aislados del

Tabla 3. Comparación de la actividad enzimática en xilano por el método cualitativo y cuantitativo, evaluada para los seis aislamientos seleccionados en dos compost de la Sabana de Bogotá.

\begin{tabular}{|l|l|c|c|}
\hline \multirow{2}{*}{ Microorganismo } & AE cualitativa & AE cuantitativa \\
\cline { 3 - 4 } & & $\%$ & nkat/s mL-1 \\
\hline \multirow{3}{*}{ Compost 1 } & Bacillus sp. 1 & 77,5 & 15,64 \\
\cline { 2 - 4 } & Aspergillus sp. 1 & 66,9 & 53,96 \\
\cline { 2 - 4 } & Streptomyces sp. 1 & 57,7 & 18,40 \\
\hline \multirow{3}{*}{ Compost 2 } & Bacillus sp. 2 & 52,6 & 7,31 \\
\cline { 2 - 4 } & Penicillium sp. & 54,8 & 48,53 \\
\cline { 2 - 4 } & Streptomyces sp. 2 & 62,7 & 38,21 \\
\hline
\end{tabular}



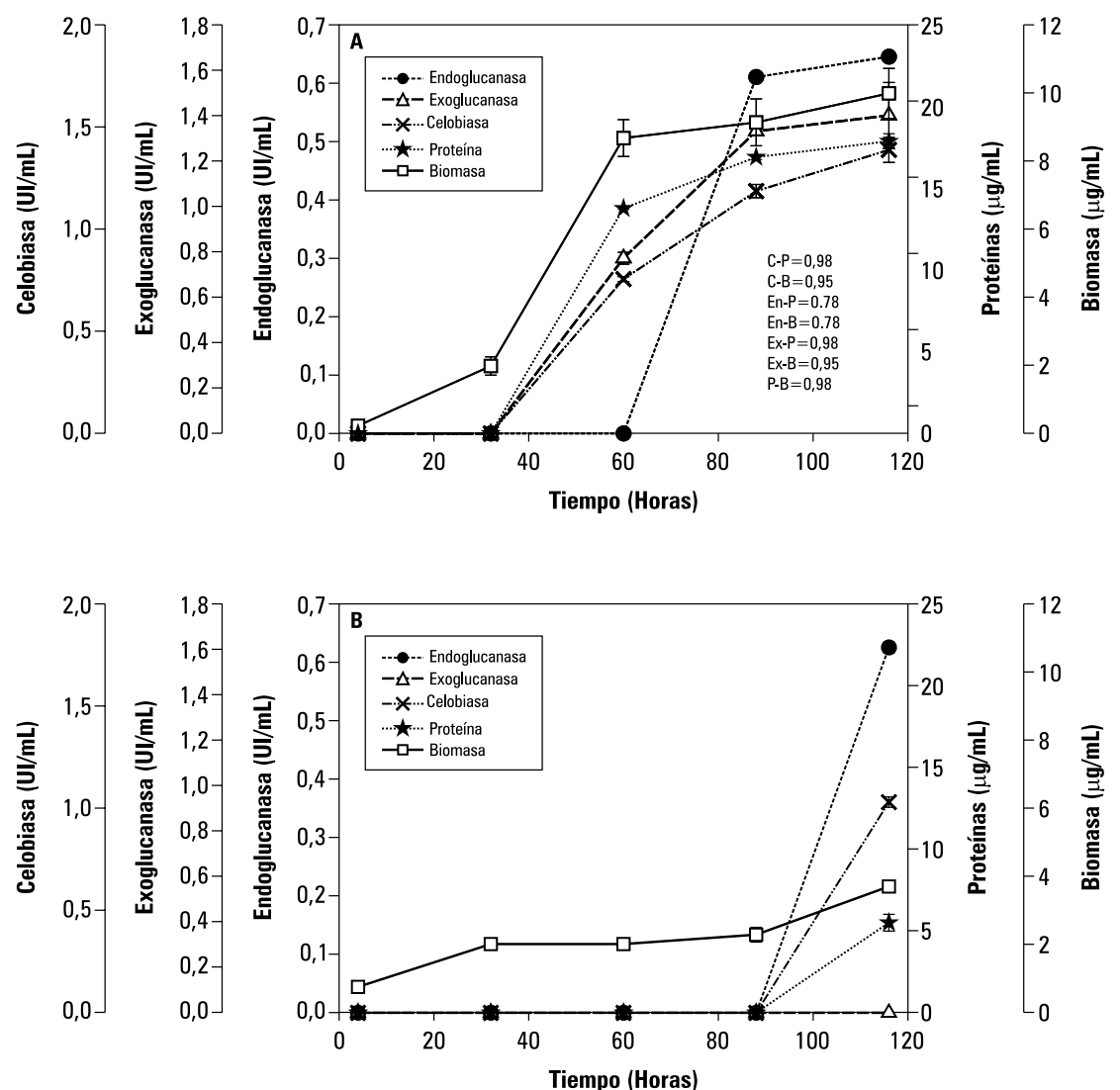

Figura 3. Crecimiento y actividad enzimática celulolítica. A, Aspergillus sp. 2; B Streptomyces sp. 3. C, celobiasa: $P$, proteínas solubles; En, endoglucanasa; Ex, exoglucanasa; $B$, biomasa. Coeficientes de correlación entre las variables C-P, C-B, En-P, En-B, Ex-P, Ex-B, P-B.

compost 2. Estos dos microorganismos fueron los únicos que presentaron halos de degradación con grado 3 de intensidad en las pruebas cualitativas.

El hongo Aspergillus sp. 2 presentó una buena correlación entre las variables $(>0,78)$, lo que indicaría que el crecimiento del microorganismo está relacionada con el aumento de proteínas solubles y las actividades degradadoras sobre el sustrato. Aspergillus sp. 2 presentó actividad a las 60 h para los tres tipos de enzimas, endo y exoglucanasa y celobiasa (figura 3A). Especies del género Aspergillus han sido reportadas por su liberación de celulasas extracelulares (Lynd et al., 2002) como por ejemplo A. niger (Kang et al., 2004) y A. terreus (Gao et al., 2008).

El actinomiceto Streptomyces sp. 3 presentó su actividad a las $116 \mathrm{~h}$ y solo tuvo actividad endoglucanasa y celobiasa (figura 3B). Hay que resaltar que el actinomiceto Streptomyces sp. 3 tiene un crecimiento de biomasa leve antes de las $116 \mathrm{~h}$, que podría estar relacionado a la actividad degradadora del sustrato que no es detectada por los métodos utilizados.

En el estudio realizado por Ramírez y Coha (2003), para actinomicetos termofílicos con ac- 
tividades a las $72 \mathrm{~h}$, se reportan las 10 mejores cepas de actinomicetos celulolíticos termófilos, las cuales tienen actividad endoglucanasa entre 1,01 y $2,10 \mathrm{UI} / \mathrm{mL}$, exoglucanasa entre 0,28 y $0,33 \mathrm{UI} / \mathrm{mL}$, y $\beta$-glucosidasa entre 0,30 y 0,62 $\mathrm{UI} / \mathrm{mL}$.

El actinomiceto Streptomyces sp. 3 tuvo actividad a las $116 \mathrm{~h}$ y fue de $0,63 \mathrm{UI} / \mathrm{mL}$ para endoglucanasa y $1,03 \mathrm{UI} / \mathrm{mL}$ para celobiasa, al comparar entre estos resultados y los reportados en el estudio mencionado se ve que para la endoglucanasa la actividad es baja y para la celobiasa es alta. Nsereko et al. (2000) observaron que la actividad enzimática varía mucho entre productos enzimáticos, aunque se originen de un mismo microorganismo, lo cual puede deberse a las enzimas que contenga el producto y su habilidad para ajustarse al sitio activo de cada sustrato.

Dentro de las razones por las cuales hubo ausencia de la actividad en medio líquido de las otras cepas microbianas evaluadas para celulosa se observa baja actividad en medio solido (grado 2) y que quizás estas cepas necesitaban más tiempo para iniciar su actividad o que habría sido útil adicionar lactosa y Tween 80 al medio, ya que según Crawford y McCoy (1972) y Ramírez y Coha (2003), la lactosa conjuntamente con la CMC permite una adecuada expresión de las enzimas, coayudada por el Tween 80 , un surfac- tante no iónico que estimula la liberación de las celulasas al medio extracelular.

\section{CONCLUSIONES}

- El compost 2 fue mejor para el aislamiento de microorganismos degradadores de xilano y celulosa que el compost 1.

- Se encontraron 46 microorganismos con potencial para degradar xilano siendo promisorios el hongo Aspergillus sp. 1 del compost 1 y el hongo Penicillium sp. y el actinomiceto Streptomyces sp. 2 del compost 2.

- El compost 2 presentó microorganismos promisorios para la degradación de celulosa como el hongo Aspergillus sp. 2 y el actinomiceto Streptomyces sp. 3.

- El método cualitativo utilizado para evaluación de actividad enzimática en xilano no refleja una relación directa con el método cuantitativo para los aislamientos seleccionados.

- Para la selección de microorganismos que degraden sustratos complejos, es necesario mejorar los métodos de evaluación cualitativa para que sea más eficiente y confiable el proceso de selección de aislamientos.

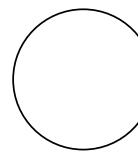

\section{REFERENCIAS BIBLIOGRÁFICAS}

Abdel-Sater, M.A. y A.H.M. El-Said. 2001. Xylan-descomposing fungi and xylanolytic activity in agricultural and industrial wastes. Intl. J. Biodetr. Biodegr. 47, 15-21.

Antanopoulos, V.T.; M. Hernandez; M.E. Atlas; E. Mavrakos y A. S. Ball. 2001. The use of extracellular enzymes from Streptomyces albus ATCC 3005 for the bleaching of eucalyptus kraft pulp. Appl. Microbiol. Biotechnol. 57, 92-97.
Bailey, M.J.; P. Biely y K. Poutanen. 1992. Inter-laboratory testing of methods for assay of xylanase activity. J. Biotech. 23, 257-270.

Chávez, R.; P. Bull y J. Eyzaguirre. 2006. The xylanolytic enzyme system from the genus Penicillium review. J. Biotech. 123, 413-433.

Cooper, R.M. y R.K. Wood. 1980. Cell wall degrading enzymes of vascular wilt fungi. Physiol. Plant Pathol. $16,285-300$. 
Crawford, D.L. y E. McCoy. 1972. Cellulases of Thermomonospora fusca and Streptomyces thermodiastaticus. Appl. Microbiol. 24, 150-152.

Curotto, E.; M. Concha; V. Campos; A.M.F. Milagres y N. Duran. 1994. Production of extracellular xylanases by Penicillium janthinellum. Effect of select growth conditions. Appl. Biochem. Biotechnol. 48, 107-116.

Ferreira, G.L.; C.G. Boer y R.M. Peralta. 1999. Production of xylanolytic enzymes by Aspergillus tamarii in solid state fermentation. FEMS Microbiol. Lett. 173, 335-339.

Gao, J.; H. Weng; D. Zhu; M. Yuan; F. Guan e Y. Xi. 2008. Production and characterization of cellulolytic enzymes from the thermoacidophilic fungal Aspergillus terreus M11 under solid-state cultivation of corn stover. Bioresource Technol. 99, 7623-7629.

Hunter-Cevera, J.C.; M.E. Fonda y A. Belt. 1986. Isolation of cultures. pp. 3-23. En: Demain, A.L. y N. A. Solomon (eds.). Manual of industrial microbiology and biotechnology. American Society of Microbiology, Washington DC.

ICA. 2007. Informe de gestión 2007. En: http://www. ica.gov.co/getdoc/4056f7f2-a10d-42eb-8d99-aeaf5e1da839/Informe-de-Gerencia-2007.aspx; consulta: julio de 2009.

ICA. 2008. Registro de productos fertilizantes. En: http:// www.ica.gov.co/getdoc/db6d3637-5b2-4868-a6fb77d7b060c3bf/Productos_Bioinsumos_Julio8_2008. aspx; consulta: septiembre de 2008.

Kang, S.W.; Y.S. Park; J.S. Lee; S.I. Hong y S.W. Kim. 2004. Production of cellulases and hemicellulases by Aspergillus niger KK2 from lignocellulosic biomass. Bioresour. Technol. 91, 153-156.

Kuhada, R.C.; M. Manchanda y A. Singh. 1998. Optimization of xylanase production by a hyperxylanolytic mutant strain of Fusarium oxysporum. Process. Biochem. 33, 641-647.

Kulkarni, N.; A. Shendye, y M. Rao. 1999. Molecular and biotechnological aspect of xylanases. FEMS Microbiol. Rev. 23, 411-456

Lynd, L. R.; P. J. Weimer; W. H. van Zyly I. S. Pretorius. 2002. Microbial cellulose utilization: fundamentals and biotechnology. Microb. Mol. Biol. Rev. 66, 506-577

Madigan, M.; J. Martinko y J. Parker. 2000. Biología de los microorganismos. 8a ed. Prentice Hall, Madrid.

Maheswari, M.U. y T.S. Chandra. 2000. Production and potential applications of a xylanase from a new strain of Streptomyees cuspidosporous. World J. Microbiol. Biotechnol. 16, 257-263.
Marx, M.C.; M. Wood y S.C. Jarvis. 2001. A microplate fluorimeteric assay for the study of enzyme diversity in soils. Soil Biol. Biochem. 33, 1633-1640.

Melgarejo, L.M.; J. Sánchez; A. Chaparro; F. Newmark; M. Santos-Acevedo; C. Burbano y C. Reyes. 2002. Aproximación al estado actual de la bioprospección en Colombia. Universidad Nacional de Colombia, Bogotá.

Mikán, J. y D. Castellanos. 2004. Screening para el aislamiento y caracterización de microorganismos y enzimas potencialmente útiles para la degradación de celulosas y hemicelulosas. Rev. Colomb. Biotecnol. 4(1), 58-71.

Miller, G.L. 1959. Use of dinitrosalisylic reagent for the determination of reducing sugar. Anal. Chem. 31, 426-428.

Mondini, C.; F. Farnasier y T. Sinicco. 2004. Enzymatic activity as a parameter for the characterization of the composting process. Soil Biol. Biochem. 36, 1587-1594.

Morales, L. 2006. Aislamiento, selección y evaluación de la actividad celulolíticos de cuatro cepas de hongos nativos de Costa Rica. Trabajo de grado. Escuela de Ingeniería en Biotecnología, Instituto Tecnológico de Costa Rica, Cartago, Costa Rica.

Nelson, N. 1944. A photometric adaptation of Somogyi method for the determination of glucose. J. Biol. Chem. 153, 375-380.

Nsereko L.V.; P.D. Morgavi; M.L. Rode; A.K. Beauchemin y A.T. McAllister. 2000. Effects of fungal enzyme preparations on hydrolysis and subsequent degradation of alfalfa hay fiber by mixed rumen microorganisms in vitro. Anim. Feed Sci. Techn. 88, 153-170.

Okeke, B.C. y S.J.C. Obi. 1994. Lignocellulose and sugar compositions of some agro-waste materials. Bioresource Technol. 47, 283-284.

Oliveira, L.A.; L.F.A. Porto, y E.B. Tambourgi. 2006. Production of xylanase and protease by Penicillium janthinellum CRC 87M-115 from different agricultural wastes. Bioresource Technol. 97(6), 862-867.

Paul, E.A. y F.E. Clark. 1996. Soil microbiology and biochemistry. $2 a$ ed. Academic Press, San Diego, CA.

Pedroza, A.M.; B.E Quevedo y A.M. Matiz. 2007. Manual de laboratorio de procesos biotecnológicos. Departamento de Microbiología, Facultad de Ciencias, Pontificia Universidad Javeriana, Bogotá.

Pham, P.L.; P. Taillandier; M. Delmas y P. Strehaiano. 1998. Production of xylanases by Bacillus polymyxa using lignocellulosic wastes. Ind. Crops Products 7, 195-203. 
Poorna, A. y P. Prema. 2007. Production of cellulose-free endocylanase from novel alkalophilic thermotolerent Bacillus pumilus by solid-state fermentation and its application in wastepaper recycling. Bioresource Technol. 98, 485-490.

Ramírez, P. y J.M. Coha. 2003. Degradación enzimática de celulosa por actinomycetes termófilos: aislamiento, caracterización y determinación de la actividad celulolítica. Revista Peruana de Biología 10(1), 67-77.

Saber, M.S. 2001. Clean biotechnology for sustainable farming. Eng. Life Sci. 6, 1-7.

Somogyi, M. 1952. Note on sugar determination. J. Biol. Chem. 195, 19-23.

Suquilanda, M.B. 1996. Agricultura orgánica. Alternativas tecnológicas del futuro. Ediciones UPS, Quito.
Sztern D. y M. Pravia. 1999. Manual para la elaboración de compost, bases conceptuales y procedimientos. Organización Panamericana de la Salud, Montevideo.

Techapun, C.; T. Charoenrat; N. Poosaran; M. Watanabey K. Sasak. 2002. Thermostable and alkaline-tolerant cellulase-free xylanase produced by thermotolerant Streptomyces sp. Ab106. J. Bioscience Bioengineering 93(4), 431-433

Vargas-García, M.C.; M.J. López; F. Suárez y J. Moreno. 2005. Laboratory study of inocula production for composting processes. Bioresource Technol. 96(7), 797-803

Zor, T. y Z. Selinger. 1996. Linearization of the Bradford protein assay increases its sensitivity: Theoretical and experimental studies. Anal. Biochem. 236, 302-308. 